\title{
Purification, and Characterization of Polysaccharides of Some Plants and Utilized in Nanocarriers ${ }^{\dagger}$
}

\author{
Teeshalini Kudaiyappan ${ }^{1}, \mathrm{Ng}$ Xiao Qi ${ }^{1, *}$
}

1 Department of Biomedical Sciences, Faculty of Medicine and Biomedical Sciences, MAHSA University, Jalan SP2, Bandar Saujana Putra, 42610, Jenjarom, Selangor, Malaysia

* Correspondence: angelngxiaoqi0903@gmail.com;

$\dagger$ Presented at International e-Conference on Bioengineering for Health and Environment (ICBHE 2020)

Received: 5.07.2020; Revised: 10.07.2020; Accepted: 12.07.2020; Published: 15.07.2020

\begin{abstract}
In this study, drug-loaded nanocarrier made of plant gum polysaccharides was used for in vitro drug delivery. Purified gum was subjected to characterization and nanocarriers synthesis. Purified polysaccharides were having good antioxidant activity and antibacterial activity. The nanocarriers were synthesized using STMP, where the size was around $200 \mathrm{~nm}$. It was delivering the drug good and possessing antibacterial activity.
\end{abstract}

Keywords: Nanocarrier; polysaccharides; drug delivery; plant gum; antibacterial activity.

(C) 2020 by the authors. This article is an open-access article distributed under the terms and conditions of the Creative Commons Attribution (CC BY) license (https://creativecommons.org/licenses/by/4.0/).

\section{Funding}

This research received no external funding.

\section{Acknowledgments}

This research has no acknowledgment.

\section{Conflicts of Interest}

The authors declare no conflict of interest. 